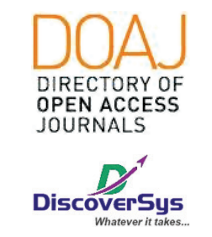

Published by DiscoverSys

\section{Management of dentoalveolar fracture by using rigid wire and composite splint: A case report}

\author{
Firstyananda $\mathrm{W}^{1 *}$ Sjamsudin $\mathrm{E}^{2}$
}

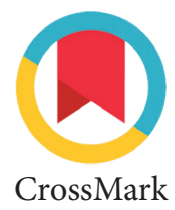

CrossMark

\title{
ABSTRACT
}

Introduction: Dentoalveolar fractures in adults often occur in the context of daily activities and traffic accidents. Crown fracture is the most common type of lesion, followed by tooth mobility.

Case: A 67-year-old woman came to the Emergency Department with bleeding from the mouth because she fells down and her lips hit the bathroom floor. There was no history of unconsciousness, vomiting, and bleeding from ear and nose. The extraoral examination found an asymmetrical face, hematoma on the right eye area, nasolabial region and chin. Edema and hematoma on the upper and lower lip. The intraoral examination was found generalized hyperemia gingiva. The diagnosis was dentoalveolar fracture 12, 22 with crown fracture of teeth 11, 21, 22 accompanied by mobility grade 2 of 12, 11 . First treatments are wound debridement, splinting with rigid wire and composite splint, and selective grinding. Panoramic references and prescribing antibiotics and analgesics. Post-action instructions include maintaining oral hygiene, soft diet, radices removal, and return for splinting control. Treatment results show good soft and hard tissue healing.

Conclusion: Rigid wire and composite splint are one of the most common and easy fixation techniques to treat dentoalveolar fractures. Simple tools and techniques make rigid wire and composite splint a good treatment for simple dentoalveolar fractures.
${ }^{1}$ Resident Oral and Maxillofacial Surgery Faculty of Dentistry, Padjadjaran University and Hasan Sadikin General Hospital ${ }^{2}$ Staff of Oral and Maxillofacial Surgery Faculty of Dentistry, Padjadjaran University

${ }^{*}$ Correspondence to: Firstyananda W, Resident Oral and Maxillofacial Surgery Faculty of Dentistry, Padjadjaran University and Hasan Sadikin General Hospital wimfirstyananda@gmail.com

Diterima: 2018-05-15 Disetujui: 2018-06-1 Diterbitkan: 2018-08-1
Keywords: Dentoalveolar Fracture, Tooth Mobility, Splinting

Cite This Article: Firstyananda, W., Sjamsudin, E. 2018. Management of dentoalveolar fracture by using rigid wire and composite splint: A case report. Intisari Sains Medis 9(2): 85-88. D0I: 10.1556/ism.v9i2.266

\section{INTRODUCTION}

Dentoalveolar fractures are the breakdown of hard tissue continuity in the dental and alveolar structures. ${ }^{1}$ Dentoalveolar trauma involves the components of dentition, periodontal tissue, and alveolar bone that may occur separately or simultaneously. ${ }^{2}$ Trauma of the teeth, especially the laceration and avulsion can cause alveolar bone fractures which can lead to tooth loss and can occur in children, adolescents, and adults. ${ }^{2,3,4}$ Facial trauma can cause tooth luxation or tooth loss. ${ }^{4}$

In adults, it is often caused by falling, sports activities, traffic accidents, etc. As of trauma may depends on the type, location, and direction of pressure. ${ }^{1}$ Various kinds of dentoalveolar trauma are enamel fractures, uncomplicated (enamel-dentin) and complicated (enamel-dentin-pulp) fractures, crown-root fractures, concussive, luxation, and avulsion. ${ }^{3}$ The uncomplicated fracture does not involve the pulp and is divided into (1) Infraction, the incomplete crack in the enamel without loss of tooth structure, (2) The enamel fracture is referred to as Ellies Class I Fracture. The enamel fracture is given grinding treatment and sharp angular grinding, or restoration of the missing tissue if the prognosis is good. (3) Fracture of crown without pulp involvement (Ellies Class II Fracture). This type of treatment is done with composite restoration or crown making in the absence of luxation.

Complicated fractures involve enamel, dentin, and pulp which can also be referred to as Class III Ellies Fracture and root fracture. ${ }^{5}$ Dentoalveolar and maxillofacial injury can cause pain, inflammation, and can impair the functioning of the mouth. ${ }^{3}$ indicate an alveolar bone fracture. Pulp necrosis may occur around the root region. ${ }^{6}$

In 2003 until 2005 at the dentoalveolar trauma center of Pontifical Catholic University, Parana, Brazil, the dentoalveolar trauma case became one of the most serious problems in dentistry with an incidence prevalence of 647 patients. Results of Indonesia Basic Health Research show that the prevalence of trauma in 2004 (56.818 cases) and increased in 2005 (72.281 cases). ${ }^{2}$ Crown fractures are the most common (65-75\%) and followed by luxation tooth $(8-20 \%)^{1}$

The high prevalence of trauma must form a balanced with adequate medical intervention and occupational facilities. ${ }^{2}$ Failure to treat dentoalveolar fractures is usually found when treatment is delayed and the immobilization techniques or equipment and materials selected are not appropriate. Also, malocclusion, and tooth mobility may also 

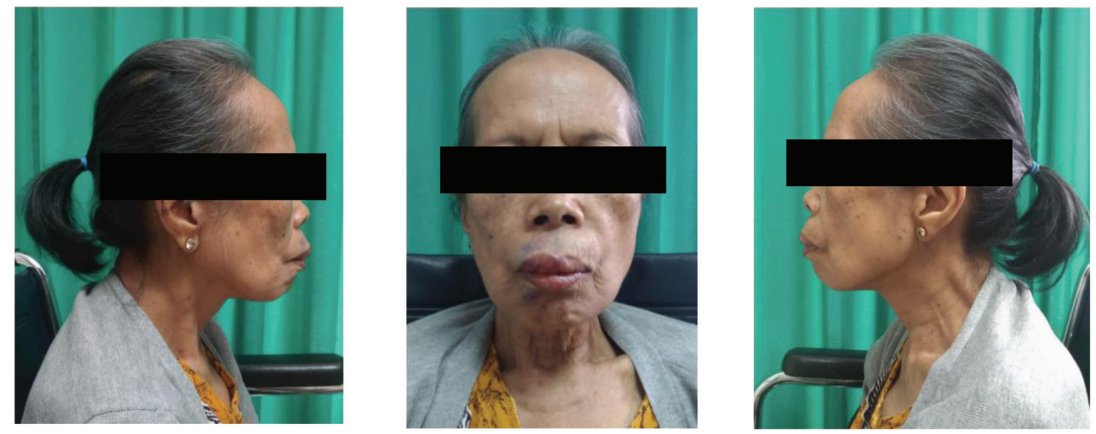

Figure 1 Extra Oral Examination

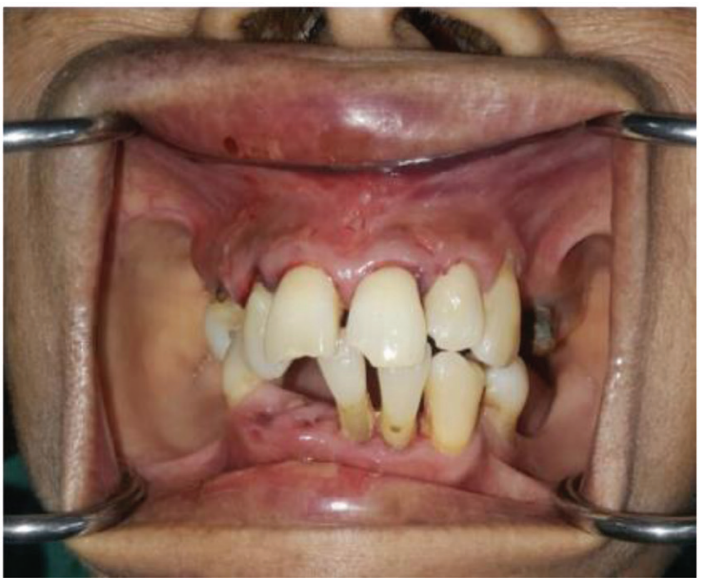

Figure 2 Intra Oral Examination

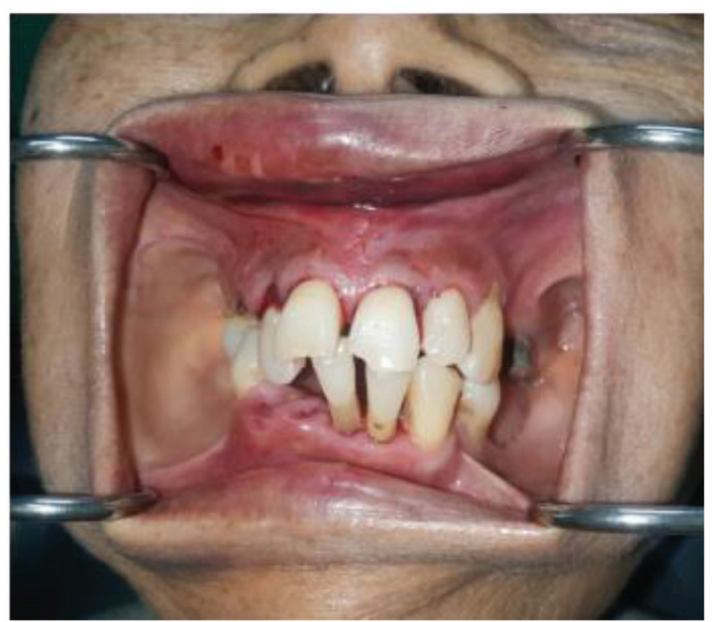

Figure 3 Post Debridement

Immediate handling can improve the success of care. ${ }^{4}$ Dentists and patients in their actions require guidance for best, effective, and efficient outcomes. ${ }^{7}$ The implementation of dentoalveolar fractures will be described in the case reports section.

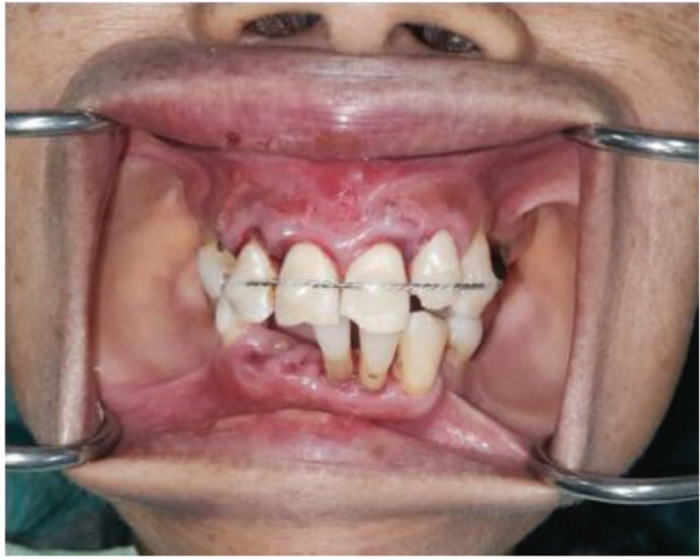

Figure 4 Post Treatment

\section{CASE REPORT}

A 67-year-old woman came to the Emergency Department with bleeding from the mouth because she fells down and her lips hit the bathroom floor. There was no history of unconsciousness, vomiting, and bleeding from ear and nose. Previously, patients were taken to a private hospital in the Cikutra area and given Tetanus Toxoid injection and $500 \mathrm{mg}$ Amoxicillin antibiotics and Sodium Diclofenac (NSAID) $25 \mathrm{mg}$. Then the patient referred to Emergency Department of Padjadjaran University Hospital for further treatment.

Extraoral examinations are an asymmetrical face, there is a hematoma in the right eye area, nasolabial region, and chin. Edema and hematoma on the upper and lower lip (Figure 1). The intraoral examination found generalized hyperemia gingiva. The diagnosis was dentoalveolar fracture 12, 22 with crown fracture of teeth 11 , 21,22 accompanied by mobility grade 2 of 12,11 (Figure 2)

Treatments for this patient are; wound debridement and splinting wire installation fixed using composite and selective grinding (Figure 3 and 4 ). Patients were recruited for panoramic roentgen photographs and prescribed antibiotic Amoxicillin $500 \mathrm{mg} 3$ times daily and Sodium Diclofenac $25 \mathrm{mg} 2$ times daily. Post-treatment instruction is to maintain oral hygiene and soft diet. Plan to performed radices of teeth at the Oral Surgery Department and instructed for splinting control after two weeks. Treatment results show good healing of soft tissue and hard tissue injury. 


\section{DISCUSSION}

Diagnosis of dentoalveolar fractures must consider anamnesis and clinical examination carefully. The initial phases of a comprehensive history of the trauma are the patient's data, when, where, how can occur, what initial treatment has been made, whether there is a tooth fracture at the site, the general condition of the patient, a history of systemic disease, and mastication. ${ }^{4}$

The goal of treating dentoalveolar trauma is to restore the normal function of tooth and digestive organs. Treatment of trauma is divided into 2 stages, immediate care after trauma (emergency treatment) and treatment for dental or alveolar bone with trauma. Emergency care is very important and should be done immediately because it is associated with prognosis. Treatments include cleaning, suturing, relieving pain, and preventing infection. ${ }^{4}$ Definitive treatment are repositioning of alveolar or traumatized tooth bone and then fixation. The technique of repositioning of the teeth and the alveolar part undergoing trauma / luxation can be done by fingers or tools. The length of immobilization is based on the degree of tooth luxation, bone support, tooth root condition. Usually the duration of treatment is about 6-7 weeks. ${ }^{4}$

Treatment on the reported case is rigid wire and composite splint. According to the American Association of Endodontics, splitting is something rigid or flexible or both used to support, protect, or immobilize teeth, reimplantation, fracture, or relate to the treatment of endodontic surgical procedures. Splinting of teeth is needed to stabilize the laceration by trauma, transplantation, dental root fracture, tooth loss or lack of supporting tissue caused by periodontal abnormalities, external resorption, or apicoectomy. ${ }^{8,9}$

According to the case report section, the patient came with intraoral bleeding condition caused by trauma resulting in a dentoalveolar fracture. The first treatment performed is wound debridement and then antibiotics and analgesics to relieve pain. Antibiotics are given because periodontal ligaments cannot avoid salivary contamination that may contain microorganisms after trauma of the teeth. ${ }^{10}$

Trauma causes some teeth to mobile and therefore the patient is splinting with Rigid Wire and Composite Splint. Rigid wire and composite splint is chosen because it is easy to do and uses simple material tool, rigid wire on a tooth that experiences mobility and fixed with a composite. The surface of the labial (two-thirds crown length) etching \pm 30 seconds, rinsed, and applied in a composite which then in the polymerization of ultraviolet light. Composite polymerization starts from a healthy tooth to a traumatized tooth. The most distal part of the wire is cut or can use bur. Rigid wire and composite splint should extend 2 to 3 teeth laterally from a traumatized tooth. ${ }^{8}$ Patient also do selective grinding and removal of some residual roots of her teeth to prevent a focal infection. Patient were also instructed for splinting control two weeks later.

The result of treatment is there healing process wounds both soft tissue and hard tissue. Treatment of dentoalveolar fracture should reduce and restore the fracture in the correct position and then fixation until the bone begins to improve. Excellent immobilization tools and techniques can enhance the healing process and increase the success rate. ${ }^{4}$ The purpose of dental splinting is to stabilize the tooth as long as necessary to ensure no trauma and to protect new periodontal tissue attachment. Bone sockets continuous remodeling by stimulus-response and cementum growth slowly. After reimplantation, the new epithelial junction is reestablished within seven days, and supracrestal and bone marrow connective tissue are the main sources for proliferation of connective tissue. ${ }^{8}$

After a lateral luxation of the tooth, immediate repositioning and stabilizing the teeth anatomically to the correct position can increase the recovery of periodontal ligaments and neurovascular supply. The splinting period is indicated for periodontal therapy for 2-4 weeks, but some cases that lose periodontal support or marginal bone damage should splinting time be increased to 8 weeks. ${ }^{11}$ The perfect formation of a periodontal ligament takes about four months. ${ }^{8}$ The correct diagnosis should associate with rapid treatment and long control periods for the treatment to work successfully. ${ }^{11}$

\section{CONCLUSION}

Dentoalveolar fracture is the breakdown or breakage of hard tissue continuity in the tooth structure and alveolus. In adults it is often caused by falling, sports activities, traffic accidents, etc. Rigid wire and the composite splint are one of the most common and easy fixation techniques to treat dentoalveolar fractures. The purpose of dental splinting is to stabilize the tooth for as long as necessary to ensure no trauma and to protect the new periodontal tissue attachment. Simple tools and techniques make rigid wire and composite splint a good treatment for simple dentoalveolar fractures.

\section{REFERENCES}

1. Pastor BS, et al. Treatment and Restoration of Adult Dentoalveolar Trauma: A clinical Case Report. J Clin Exp Dent. 2016;8(5):634-647.

2. Arbi TA, Novita CF, Mulya. Tingkat Pengetahuan Dokter Gigi Muda terhadap Penanganan Trauma Dentoalveolar di Rumah Sakit Gigi Mulut Universitas Syiah Kuala. Cakradonya Dent J. 2016;8(2):98-104. 
3. Soukup JW, Synder CJ. Traumatic Dentoalveolar and Maxillofacial Injuries in cats : Overview of Diagnosis and Management. J Feline Med Surg. 2014;16(2):915-927.

4. Samsudin E. Immobilization Tools and Materials Selection in Dentoalveolar Fracture. Padjadjaran Journal of Dentistry. 2007;19(3):119-124.

5. Samra FMA. Dentoalveolar Injuries Classification Management Biological Consequences. J Dent Health Oral Disord Ther. 2014;1(4):1-6.

6. Gurmacher Z, Peled E, Norman D, Lin Shaul. Alveolar Bone Fracture: Pathognomonic Sign for Clinical Diagnosis. The Open Dentistry Journal. 2015.119(2) :8-14.

7. Anthony J. International Association of Dental Traumatology Guidelines for The Management of Traumatic Dental Injuries : 1. Fractures and Luxations of Permanent Teeth. Dental Traumatology. 2012;28(3):2-12.

8. Oikarinen K. Tooth Splinting : A Review of The Literature and Consideration of The Versatility of A Wire-Composite Splint. Endod Dent Traumato. Finlandia. 1990;6(3): 237-250.
9. Bakar A. Kedokteran Gigi Klinis. Yogyakarta : Penerbit Quantum Sinergis Media. 2012. p.140.

10. Croll TP. Bonded Composite Resin/Ligature Wire Splint for Stabilization of Traumatically Displaced Teeth. Quintessence International. 1991;22(1):17-21.

11. Rossi MD, et al. Management of a Complex Dentoalveolar Trauma: A Case Report. Braz Dent J. 2009;20(3):259-262.

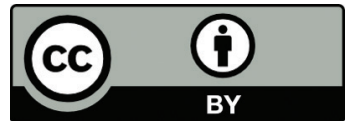

This work is licensed under a Creative Commons Attribution 